\title{
Front Matter: Volume 7633
}

, "Front Matter: Volume 7633," Proc. SPIE 7633, Network Architectures, Management, and Applications VII, 763301 (3 December 2009); doi: 10.1117/12.853556 SPIE. Event: Asia Communications and Photonics, 2009, Shanghai, Shanghai , 


\title{
PROCEEDINGS OF SPIE
}

\section{Network Architectures, Management, and Applications VII}

\author{
Ken-ichi Sato \\ Yuefeng Ji \\ Lena Wosinska \\ Jing Wu \\ Editors \\ 2-6 November 2009 \\ Shanghai, China \\ Cosponsored by \\ Optical Society of America \\ IEEE Photonics Society \\ SPIE \\ Chinese Optical Society \\ China Institute of Communications \\ Local Organizing Committee \\ Shanghai Jiao Tong University \\ Shanghai Institute of Optics and Fine Mechanics \\ Alcatel-Lucent \\ Fudan University \\ Published by \\ SPIE \\ Optical Society of America \\ IEEE Photonics Society
}

Volume 7633 
The papers included in this volume were part of the technical conference cited on the cover and title page. Papers were selected and subject to review by the editors and conference program committee. Some conference presentations may not be available for publication. The papers published in these proceedings reflect the work and thoughts of the authors and are published herein as submitted. The publisher is not responsible for the validity of the information or for any outcomes resulting from reliance thereon.

Please use the following format to cite material from this book:

Author(s), "Title of Paper," in Network Architectures, Management, and Applications VII, edited by Ken-ichi Sato, Yuefeng Ji, Lena Wosinska, Jing Wu, Proceedings of SPIE-OSA-IEEE Asia Communications and Photonics, SPIE Vol. 7633 (SPIE, Bellingham, WA, 2009) Article CID Number.

ISSN 0277-786X

ISBN 9780819480354

Published by

SPIE

P.O. Box 10, Bellingham, Washington 98227-0010 USA

Telephone +1 3606763290 (Pacific Time) · Fax +1 3606471445

SPIE.org

Optical Society of America

2010 Massachusetts Ave., N.W., Washington, D.C., 20036 USA

Telephone +1 2022238130 (Eastern Time) · Fax +1 2022231096

OSA.org

IEEE Photonics Society

445 Hoes Lane, Piscataway, New Jersey, 08855 USA

Telephone +1 7325628434 (Eastern Time) · Fax +1 7325628434

IEEE.org

Copyright (C) 2009, Society of Photo-Optical Instrumentation Engineers, Optical Society of America, and IEEE Photonics Society.

Copying of material in this book for internal or personal use, or for the internal or personal use of specific clients, beyond the fair use provisions granted by the U.S. Copyright Law is authorized by SPIE subject to payment of copying fees. The Transactional Reporting Service base fee for this volume is $\$ 18.00$ per article (or portion thereof), which should be paid directly to the Copyright Clearance Center (CCC), 222 Rosewood Drive, Danvers, MA 01923. Payment may also be made electronically through CCC Online at copyright.com. Other copying for republication, resale, advertising or promotion, or any form of systematic or multiple reproduction of any material in this book is prohibited except with permission in writing from the publisher. The CCC fee code is 0277-786X/09/\$18.00.

Printed in the United States of America.

Publication of record for individual papers is online in the SPIE Digital Library.

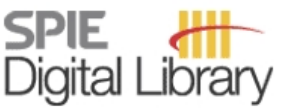

SPIEDigitalLibrary.org

Paper Numbering: Proceedings of SPIE follow an e-First publication model, with papers published first online and then in print and on CD-ROM. Papers are published as they are submitted and meet publication criteria. A unique, consistent, permanent citation identifier (CID) number is assigned to each article at the time of the first publication. Utilization of CIDs allows articles to be fully citable as soon they are published online, and connects the same identifier to all online, print, and electronic versions of the publication. SPIE uses a six-digit CID article numbering system in which:

- The first four digits correspond to the SPIE volume number.

- The last two digits indicate publication order within the volume using a Base 36 numbering system employing both numerals and letters. These two-number sets start with 00, 01, 02, 03, 04, 05, 06, 07, 08, 09, 0A, $\mathrm{OB}$... OZ, followed by 10-1Z, 20-2Z, etc.

The CID number appears on each page of the manuscript. The complete citation is used on the first page, and an abbreviated version on subsequent pages. Numbers in the index correspond to the last two digits of the six-digit CID number. 


\section{Contents}

$\begin{aligned} \text { xi } & \text { Organizing Committee } \\ \text { xiii } & \text { Conference Committee }\end{aligned}$

\section{BEST STUDENT PAPER COMPETITION}

763302 Impact of waveband capacity on protected hierarchical optical path networks [7633-55]

Y. Yamada, H. Hasegawa, K. Sato, Nagoya Univ. (Japan)

763303 A novel layer 1 virtual private network provisioning architecture in multi-domain optical networks [7633-27]

T. Sun, J. Zhang, X. Chen, Y. Zhao, D. Han, W. Gu, Y. Ji, Beijing Univ. of Posts and

Communications (China)

763304 Overlay of multicast service in WDM-PON based on dynamic wavelength reflection scheme [7633-37]

M. Zhu, Shanghai Jiao Tong Univ. (China) and SATIE Lab. (France); S. Xiao, W. Guo, H. Chen, Shanghai Jiao Tong Univ. (China); A. Wei, Univ. de Toulouse II (France); Y. Jin, W. Hu,

Shanghai Jiao Tong Univ. (China); B. Geller, ENSTA ParisTech (France)

763305 Evaluation of signaling schemes under multi-region survivable network by agent negotiations [7633-51]

B. Li, S. Huang, Y. Zhang, R. Chen, W. Gu, Beijing Univ. of Posts and Telecommunications (China)

763306 A differentiated QoS aware multipath routing algorithm for optical burst switched networks [7633-63]

Y. Chi, Peking Univ. (China); Z. Zhang, Guangxi Univ. (China); Z. Li, A. Xu, Peking Univ. (China)

763307 Impairment aware routing with service differentiation in heterogeneous WDM networks (Best Student Paper Award) [7633-49]

A. Jirattigalachote, L. Wosinska, P. Monti, KTH Royal Institute of Technology (Sweden);

K. Katrinis, A. Tzanakaki, Athens Information Technology (Greece)

763308 Clock synchronization in T-MPLS network via PTP (IEEE 1588 V2) [7633-46]

R. Chen, Y. Zhang, C. Cao, Y. Zhao, B. Li, J. Zhang, W. Gu, Beijing Univ. of Posts and

Telecommunications (China)

\section{DYNAMIC PROVISIONING}

763309 Efficient protection and grooming architectures for future optical networks (Tutorial) [7633-71]

A. K. Somani, lowa State Univ. (United States) 
7633 OA Impact of path granularity and operation interval on dynamic path network control [7633-57]

H. Ito, H. Hasegawa, K. Sato, Nagoya Univ. (Japan)

$7633 \mathrm{OB}$ Evaluations of physical and optical path level hierarchical networks to implement optical fast circuit switching [7633-56]

T. Ogawa, Y. Yamada, H. Hasegawa, K. Sato, Nagoya Univ. (Japan)

7633 OC Fault-tolerant scheduling using primary-backup approach for optical grid applications [7633-79]

M. Zhu, Shanghai Jiao Tong Univ. (China) and SATIE Lab. (France); S. Xiao, W. Guo, Shanghai Jiao Tong Univ. (China); A. Wei, Univ. de Toulouse II (France); Y. Jin, W. Hu, Shanghai Jiao Tong Univ. (China); B. Geller, ENSTA Paris Tech (France)

\section{OPTICAL ACCESS NETWORKS I}

7633 OD Challenges and opportunities for migration towards 10GPON (Invited Paper) [7633-66] H. Mickelsson, E. In De Betou, B. Skubic, S. Dahlfort, Ericsson Research, Ericsson AB (Sweden)

7633 OE Improved scheme for estimating T-CONT bandwidth demand in status reporting DBA for NG-PON [7633-64] B. Skubic, Ericsson Research, Ericsson AB (Sweden); B. Chen, KTH Royal Institute of Technology (Sweden) and Zhejiang Univ. (China); J. Chen, J. Ahmed, L. Wosinska, KTH Royal Institute of Technology (Sweden)

7633 OF A novel WDM-PON architecture enabling multicasting with color-free ONUs based on WSS and Interleaver [7633-14]

Y. Xiang, S. Xiao, Shanghai Jiao Tong Univ. (China); Z. Liu, The Chinese Univ. of Hong Kong (Hong Kong, China); M. Zhu, D. Ding, Y. Cheng, J. Wei, Shanghai Jiao Tong Univ. (China)

7633 OG Least imbalance flows decomposition algorithm for multi-region optical networks [7633-34] B. Li, S. Huang, W. Gu, Beijing Univ. of Posts and Telecommunications (China)

$7633 \mathrm{OH}$ A novel WDM-PON structure using the orthogonal FSK/ASK re-modulation scheme [7633-47] X. Liu, Y. Shao, C. Hou, X. Zheng, X. Li, S. Zou, N. Chi, Fudan Univ. (China)

7633 Ol A novel DBA algorithm supporting QoS for EPON networks [7633-80]

Y. Qiu, North China Electric Power Univ. (China)

\section{OPTICAL ACCESS NETWORKS II}

7633 0J GPON FTTH trial: lessons learned [7633-74]

E. Weis, Deutsche Telekom Labs. (Germany); R. Hölzl, Deutsche Telekom Netzproduktion GmbH (Germany); D. Brever, C. Lange, Deutsche Telekom Labs. (Germany)

7633 OK A novel OFDM-PON architecture using single-side-band OFDM for down stream and sub-carrier multiplexed ASK for up stream [7633-38]

X. Zheng, X. Liu, C. Hou, Y. Shao, S. Zou, X. Li, J. Zhang, W. Fang, N. Chi, Fudan Univ. (China) 
$7633 \mathrm{OL} \quad$ PON network designing algorithm for suboptimal deployment of optical fiber cables [7633-58]

A. Agata, Y. Horiuchi, KDDI R\&D Labs. Inc. (Japan)

$76330 \mathrm{M}$ A novel scheme of unicast and multicast in WDM-PON using reflective semiconductor optical amplifier [7633-15]

C. Yang, S. Xiao, M. Zhu, W. Xie, Shanghai Jiao Tong Univ. (China); Z. Liu, The Chinese Univ. of Hong Kong (Hong Kong, China); L. Ge, Y. Xiang, J. Wei, Shanghai Jiao Tong Univ. (China)

\section{GMPLS PROVISIONING}

7633 ON Improving the dual-failure restorability in scheduled WDM mesh networks [7633-44] Q. Li, W. Ni, Y. Li, Y. Guo, H. Zhang, X. Zheng, Tsinghua Univ. (China)

763300 Performance analysis of an improved postponed lightpath teardown strategy in multi-layer optical networks [7633-01]

N. Hua, Tsinghua Univ. (China); H. Buchta, Fraunhofer Institute for Telecommunications Heinrich-Hertz-Institut (Germany); X. Zheng, H. Zhang, B. Zhou, Tsinghua Univ. (China)

7633 OP Blocking-differentiated path provisioning in semi-dynamic survivable WDM networks [7633-18]

W. Ni, Tsinghua Univ. (China); M. Schlosser, Fraunhofer-Institute for Telecommunications Heinrich Hertz-Institut (Germany); H. Zhang, Tsinghua Univ. (China); E. Patzak,

Fraunhofer-Institute for Telecommunications, Heinrich Hertz-Institut (Germany)

\section{APPLICATIONS OF OPTICAL SYSTEMS IN NETWORKS I}

$76330 Q \quad$ Recent progress on planar lightwave circuit technology for optical communication (Invited Paper) [7633-87]

H. Takahashi, Nippon Telegraph and Telephone Corp. (Japan)

7633 OR Deflection routing in multi-channel photonic network on chip architecture [7633-52]

J. Tang, Y. Jin, Z. Chang, Shanghai Jiao Tong Univ. (China)

7633 OS Performance evaluation for optical network-on-chip interconnect architectures [7633-53]

S. Wang, H. Gu, Xidian Univ. (China)

\section{APPLICATIONS OF OPTICAL SYSTEMS IN NETWORKS II}

7633 ОT Experimental temporal and power misalignment monitoring for all-optical ultrawideband pulse based on dark RZ pulse generation [7633-45]

J. Zhang, W. Fang, Y. Shao, B. Huang, N. Chi, Fudan Univ. (China) 
NEXT GENERATION OPTICAL NETWORKS

$7633 \mathrm{OV}$ Research on capacity planning of WDM networks using improved ant colony algorithm [7633-08]

P. Luo, S. Huang, L. LV, B. Li, J. Zhang, W. Gu, Beijing Univ. of Posts and Telecommunications (China)

7633 oW The design and implementation of distributed resource manager in optical grid networks [7633-21]

S. Chen, W. Hu, W. Guo, Y. Jin, Shanghai Jiao Tong Univ. (China)

7633 0X Dynamic domain-sequencing scheme for inter-domain path computation in WDM networks [7633-13]

X. Wan, Y. Chen, H. Zhang, X. Zheng, Tsinghua Univ. (China)

7633 OY Dynamic overlay routing based on active probing measurements: an emulation study [7633-24]

X. Zhang, W. Ye, Y. Jin, Shanghai Jiao Tong Univ. (China)

\section{HYBRID WIRELESS AND OPTICAL NETWORKS}

$76330 Z$ Towards a seamless hybrid communication system (Invited Paper) [7633-81]

Y. Ye, Nokia Siemens Networks (United States); H. Zang, Sprint Advanced Technology Labs. (United States)

763310 Principle, technology, and challenge of radio over fiber (RoF) based broadband access for metro and intercity trains (Invited Paper) [7633-60]

M. M. Zhou, Shanghai Univ. of Engineering Science (China)

763311 Communication protocol based on optical low-energy-adaptive-clustering-hierarchy (O-LEACH) for hybrid optical wireless sensor networks [7633-76]

L.-S. Yan, W. Pan, B. Luo, J.-T. Liu, M.-F. XU, Southwest Jiaotong Univ. (China)

\section{SURVIVABLE NETWORKS I}

763313 Reliability-guaranteed path protection under multiple constraints [7633-62]

Y. Liu, Z. Zheng, X. Liu, Beihang Univ. (China)

763314 A PCE-based fast reroute algorithm for multi-failures in multi-domain optical networks [7633-31]

X. Cao, J. Zhang, Y. Zhao, J. Liu, D. Han, W. Gu, Beijing Univ. of Posts and Telecommunications (China)

OPTICAL PACKET SWITCHED NETWORKS

763315 High-performance multicasting schemes in optical packet switched networks (Invited Paper) [7633-86]

Y. Ji, X. Liu, J. Zhang, M. Zhang, Beijing Univ. of Posts and Telecommunications (China) 
763316 Key requirements of packet transport network based on MPLS-TP (Invited Paper) [7633-04] F. Huang, X. Yi, H. Zhang, P. Gong, Alcatel Shanghai Bell (China)

763317 An effective routing strategy through impairment-aware RWA in transparent optical network [7633-65]

W. Guo, J. Zhang, G. Gao, D. Han, W. Gu, Y. Ji, Beijing Univ. of Posts and Telecommunications (China)

$763318 \quad$ Novel multi-granularity optical switching node with wavelength management pool resources [7633-26]

G. Zhang, Q. Xiong, S. Shen, Y. Ye, Huawei Technology Co. Ltd. (China)

\section{SURVIVABLE NETWORKS II}

763319 Constraint-aware policy-enabled routing strategy for scalable multi-domain multi-layer optical networks (Invited Paper) [7633-73]

M. Zhang, Y. Ji, J. Zhang, Beijing Univ. of Posts and Telecommunications (China)

$76331 \mathrm{~A}$ On allocating redundancy links to improve robustness of complex communication network [7633-39]

Y. Zhuo, Y. Peng, K. Long, Y. Liu, Univ. of Electronic Science and Technology of China (China)

7633 1B A novel survivable traffic grooming algorithm with inter-layer sharing in IP/MPLS-over-WDM mesh networks [7633-78]

D. Gong, X. Zhang, H. Yu, X. Ling, D. Liao, Univ. of Electronic Science and Technology of China (China); H. Luo, Beijing Jiaotong Univ. (China)

7633 1C A novel segment protection with segment route scheme in multicasting survivable networks [7633-06]

Z. Zhu, W. Dong, Z. Le, X. Sun, W. Chen, Zhejiang Univ. of Technology (China)

\section{DYNAMIC LIGHTPATH CONTROL}

7633 1D Lightpath routing considering differentiated physical layer constraints in transparent WDM networks (Invited Paper) [7633-67]

L. Wosinska, A. Jirattigalachote, P. Monti, KTH Royal Institute of Technology (Sweden);

A. Tzanakaki, K. Katrinis, Athens Information Technology (Greece)

$76331 \mathrm{E}$ The challenge of controlling zero touch photonics with GMPLS (Invited Paper) [7633-16]

G. Grammel, Alcatel-Lucent (Germany)

7633 IF A dynamic routing algorithm for multi-domain photonic networks using averaged link load information [7633-59]

K. Shimada, Nagoya Univ. (Japan); S. Araki, Nagoya Univ. (Japan) and NEC Corp. (Japan); H. Hasegawa, K. Sato, Nagoya Univ. (Japan)

$76331 \mathrm{G} \quad$ Novel iterative P-cycle configure model in WDM intelligent optical network [7633-83]

B. Li, S. Huang, Y. Zhang, W. GU, Y. Zu, Beijing Univ. of Posts and Telecommunications (China) 
$76331 \mathrm{H} \quad$ Mobile agent-based platform for ASON management [7633-25]

X. Li, S. Huang, B. Guo, R. Wang, Y. Zheng, W. Gu, Beijing Univ. of Posts and

Telecommunications (China)

\section{NETWORK ARCHITECTURE}

763311 Design of hierarchical WDM networks (Invited Paper) [7633-72]

M. Razo, S. Billenahalli, W. Huang, A. Sivasankaran, L. Tang, H. Vardhan, M. Tacca,

A. Fumagalli, The Univ. of Texas at Dallas (United States); P. Monti, KTH Royal Institute of Technology (Sweden); Y. Lee, X. Liu, Z. Sui, Huawei Technologies (United States)

7633 iJ A PCE-based redundancy-aware path selection scheme for multi-layer network [7633-54] Y. Yao, Y. Zhang, C. LU, Z. Zhang, B. Li, W. Gu, Beijing Univ. of Posts and Telecommunications (China)

$76331 \mathrm{~K}$ Performance evaluation of $k$-ary data vortex networks with bufferless and buffered routing nodes [7633-23]

Q. Yang, Harvey Mudd College (United States)

7633 IL Improving robustness against the coordinated attack by removing crashed hub nodes in complex network [7633-40]

Y. Zhuo, Y. Peng, K. Long, Univ. of Electronic Science and Technology of China (China)

\section{VIRTUAL NETWORK}

$76331 \mathrm{M}$ The research of cloud computing based on service plane over optical networks [7633-50] Z. Li, D. Han, J. Zhang, X. Chen, W. Gu, Y. Ji, Beijing Univ. of Posts and Telecommunications (China)

$76331 \mathrm{~N}$ Survivability optimization and analysis of network topology based on average distance [7633-69]

Y. Li, Y. Peng, S. Du, K. Long, Y. Zhuo, Univ. of Electronic Science and Technology of China (China)

\section{POSTER SESSION}

763310 Orthogonal wavelength-division-multiplexing using SSFBGS in passive optical networks [7633-28]

Z. Zheng, Z. Qian, G. Shou, Y. Hu, Beijing Univ. of Posts and Telecommunications (China)

7633 IP Optimizing TCP window for grid over OBS networks [7633-10]

S. Peng, Z. Li, Peking Univ. (China); Z. Zhang, Peking Univ. (China) and Guangxi Univ. (China); Y. He, A. Xu, Peking Univ. (China)

$76331 Q$ A novel routing and wavelength assignment algorithm based on colored multigraph model in WDM networks [7633-09]

Q. Wu, J. Wang, X. Zhou, L. Jiang, Univ. of Science and Technology Beijing (China); Y. Deng, Univ. of York (United Kingdom) 
7633 IR A new method for solving routing and wavelength assignment problems under inaccurate routing information in optical networks with conversion capability [7633-07]

Y. Luo, Y. Zhang, W. Gu, Beijing Univ. of Posts and Telecommunications (China)

7633 is An improved multicast routing algorithm in sparse splitting optical networks [7633-11] J. Wang, X. Yu, J. Yuan, Z. Wu, Q. Wu, Univ. of Science and Technology Beijing (China)

7633 1T A RSVP-TE reservation protocol based on priority in multi-domain optical network [7633-17] J. Wang, K. Yang, Q. WU, C. Pan, Univ. of Science and Technology Beijing (China)

$76331 \mathrm{U}$ A novel fair active queve management algorithm based on traffic delay jitter [7633-02] X.-S. Wang, Computer College for Huazhong Univ. of Science and Technology (China) and State Key Lab. for New Optical Communication Technologies and Networks (China); S.-H. Yu, J.-Y. Dai, State Key Lab. for New Optical Communication Technologies and Networks (China); T. Luo, Computer College for Huazhong Univ. of Science and Technology (China)

7633 IV A novel highly reliable WDM-PON system [7633-68]

$X$. Wang, Wuhan Research Institute of Posts and Telecommunications (China); S. Wang, A. Zhang, J. Wang, Fiberhome Telecommunication Technologies Co., Ltd. (China)

7633 IW PCE-based service level agreement constraint routing strategy in multi-domain optical network [7633-32]

Y. Chen, J. Zhang, D. Han, X. Chen, Y. Zhao, W. Gu, Y. Ji, Beijing Univ. of Posts and Telecommunications (China)

$76331 \mathrm{X} \quad$ An adaptive routing algorithm for flooding performance improving in GMPLS based WDM networks [7633-29]

J. Ren, D. Han, L. Wang, G. Gao, J. Zhang, W. Gu, Y. Ji, Beijing Univ. of Posts and Telecommunications (China)

Author Index 
Downloaded From: https://www.spiedigitallibrary.org/conference-proceedings-of-spie on 26 Apr 2023

Terms of Use: https://www.spiedigitallibrary.org/terms-of-use 


\title{
Organizing Committee
}

\author{
Honorary General Chairs
}

Guofan Jin, Tsinghua University (China)

Hequan Wu, Chinese Academy of Engineering (China)

Jie Zhang, Jiao Tong University (China)

Bingkun Zhou, Chinese Optical Society (China)

General Chairs

Kwok-Wai Cheung, The Chinese University of Hong Kong (Hong Kong, China)

Sailing He, Joint Research Center of the Royal Institute of Technology (Sweden) and Zhejiang University (China)

John Zyskind, JDSU Uniphase Corporation (United States)

Technical Program Chairs

Weisheng Hu, Shanghai Jiao Tong University (China)

Ming-Jun Li, Corning, Inc., (United States)

Dennis Matthews, University of California, Davis (United States)

Local Organizing Committee Chair

Yaohui Jin, Shanghai Jiao Tong University (China)

Local Organizing Committee

Nan Chi, Fudan University (China)

Weisheng Hu, Shanghai Jiao Tong University (China)

Feng Huang, Alcatel-Lucent Shanghai Bell (China)

Ronghui Qu, Institute for Optics and Fine Mechanics (China)

Weiqiang Sun, Shanghai Jiao Tong University (China) 
Downloaded From: https://www.spiedigitallibrary.org/conference-proceedings-of-spie on 26 Apr 2023

Terms of Use: https://www.spiedigitallibrary.org/terms-of-use 


\title{
Conference Committee
}

\author{
Conference Chair
}

Ken-ichi Sato, Nagoya University (Japan)

\section{Conference Cochairs}

Yuefeng Ji, Beijing University of Posts and Telecommunications (China) Lena Wosinska, KTH Royal Institute of Technology (Sweden)

Jing Wu, Communications Research Centre Canada (Canada)

Program Committee

Xiaojun Cao, Georgia State University (United States)

Xiaowen Chu, Hong Kong Baptist University (Hong Kong, China)

Gert Grammel, Alcatel-Lucent Deutschland AG (Germany)

Wei Guo, Shanghai Jiao Tong University (China)

Hiroshi Hasegawa, Nagoya University (Japan)

Jason Jue, The University of Texas at Dallas (United States)

Jinhee Kim, KT Network Research Laboratory (Korea, Republic of)

Susumu Kinoshita, Fujitsu Laboratories, Ltd. (Japan)

Keping Long, University of Electronic Science and Technology of China (China)

Carmen Mas Machuca, Technische Universität München (Germany)

Hans Mickelsson, Ericsson (Sweden)

Paolo Monti, KTH Royal Institute of Technology (Sweden)

Carla Raffaelli, Università di Bologna (Italy)

Gangxiang Shen, Ciena Corporation(United States)

Nina Skorin-Kapov, University of Zagreb (Croatia)

Anna Tzanakaki, Athens Information Technology (Greece)

Jianping Wang, City University of Hong Kong (Hong Kong, China)

Yong Hyub Won, KAIST (Korea, Republic of)

Chenliang Zhang, China Telecom Research Institute (China)

Jie Zhang, Beijing University of Post and Telecommunications (China)

Luying Zhou, Institute for Infocomm Research (Singapore)

\section{Session Chairs}

Best Student Paper Competition

Jing Wu, Communications Research Centre Canada (Canada)

Dynamic Provisioning

George N. Rouskas, North Carolina State University (United States) 
Optical Access Networks I

Dirk Breuer, Deutsche Telekom AG (Germany)

Optical Access Networks II

Feng Huang, Alcatel-Lucent Technologies Company, Ltd. (China)

GMPLS Provisioning

Arun K. Somani, lowa State University (United States)

Applications of Optical Systems in Networks I

Ken-ichi Kitayama, Osaka University (Japan)

Applications of Optical Systems in Networks II

Lena Wosinska, KTH Royal Institute of Technology (Sweden)

Next Generation Optical Networks

Angela L. Chiv, AT\&T Laboratory Research (United States)

Hybrid Wireless and Optical Networks

Gert Grammel, Alcatel-Lucent Deutschland AG (Germany)

Survivable Networks I

Lena Wosinska, KTH Royal Institute of Technology (Sweden)

Optical Packet Switched Networks

Ken-ichi Sato, Nagoya University (Japan)

Survivable Networks II

Hiroaki Harai, National Institute of Information and Communications Technology (Japan)

Dynamic Lightpath Control

Yuefeng Ji, Beijing University of Posts and Telecommunications (China)

Network Architecture

Weiqiang Sun, Shanghai Jiao Tong University (China)

Virtual Network

Jin U. Kang, The Johns Hopkins University (United States) 